\title{
CAIX Inhibitor SLC-0111
}

National Cancer Institute

\section{Source}

National Cancer Institute. CAIX Inhibitor SLC-0111. NCI Thesaurus. Code C117728.

A sulfonamide carbonic anhydrase inhibitor with potential antineoplastic activity. Upon administration, CAIX inhibitor SLC-0111 inhibits tumor-associated carbonic anhydrase IX (CAIX), an hypoxia-inducible transmembrane glycoprotein that catalyzes the reversible reaction and rapid interconversion of carbon dioxide and water to carbonic acid, protons, and bicarbonate ions. This prevents both the acidification of the tumor's extracellular microenvironment and cytoplasmic alkalization. This increases cell death in CAIXexpressing, hypoxic tumors. CAIX is overexpressed in various tumors and plays a key role in intra- and extracellular pH regulation, cancer cell progression, survival, migration and invasion; it is also involved in resistance to both chemo- and radiotherapy. 